\title{
Optimal search strategy for clinical trials in the Latin American and Caribbean Health Science Literature Database (LILACS)
}

\author{
Clinical Trial and Meta-Analysis Unit, Federal University of São Paulo, in conjunction with the \\ Brazilian Cochrane Center - São Paulo, Brazil
}

Objective: To define and disseminate the optimal search strategy for clinical trials in the Latin American and Caribbean Health Science Literature (LILACS). This strategy was elaborated based on the optimal search strategy for MEDLINE recommended by Cochrane Collaboration for the identification of clinical trials in electronic databases. Design: Technical information. Setting: Clinical Trials and Meta-Analysis Unit, Federal University of São Paulo, in conjunction with the Brazilian Cochrane Center, São Paulo, Brazil. (http://www.epm.br/cochrane). Data; LILACS/CD-ROM (Latin American and Caribbean Health Science Information Database), 27th edition, January 1997, edited by BIREME (Latin American and Caribbean Health Science Information Center). LILACS Indexes 670 journals in the region, with abstracts in English, Portuguese or Spanish; only 41 overlap in the MEDLINE-EMBASE. Of the 168.902 citations since $1982,104,016$ are in human trials, and 38,261 citations are potentiality clinical trials. Search strategy was elaborated combining headings with text word in three languages, adapting the interface of the LILACS. We will be working by locating clinical trials in LILACS for Cochrane Controlled Trials Database. This effort is being coordinated by the Brazilian Cochrane Center.

UNITERMS: Clinical Trial. Meta-Analysis. Electronic Databases. Location and Selecting studies. Information Storage and Retrieval. MEDLINE. LILACS.

\section{INTRODUTION}

A $\mathrm{n}$ unbiased search is the key to a relevant systematic review. To protect against bias and ensure that all relevant data are included in a review, it is important to use multiple sources to identify studies and a systematic approach to select among them ${ }^{1}$. As for sources, Latin America and Caribbean have the LILACS$^{2}$, an electronic database (CD-ROM and Online) which indexes regional literature from more than 670

\author{
Address for correspondence: \\ Aldemar Araujo Castro \\ Unidade de Ensaios Clínicos e Meta-Análise \\ Universidade Federal de São Paulo \\ Rua Pedro de Toledo, 598 \\ São Paulo/SP - Brasil - CEP 04039-001
}

journals, with 168,904 citations incorporated since 1982 and abstracts in English, Portuguese or Spanish. The United States National Library of Medicine's medical subject headings (MeSH) vocabulary is used to index each LILACS citation. LILACS is edited by BIREME (Latin American and Caribbean Health Science Information Center), in the city of São Paulo, Brazil. Currently, BIREME is an agency of the Pan-American Health Organization / World Health Organization.

Of the 670 journals indexed in LILACS, only 41 overlap with MEDLINE-EMBASE ${ }^{2}$. Therefore, the use of LILACS for identifying clinical trials and systematic reviews should be a part of every search strategy. The Cochrane Schizophrenia Reviews Group (CSRG), in just one previous effort, identified 1,391 trials using LILACS alone ${ }^{3}$.

Our focus was to adapt the optimal search strategy for randomized controlled trials proposed by the Cochrane Collaboration by incorporating ideas from the CSRG to formulate the optimal search strategy for using LILACS. 


\section{OPTIMAL SEARCH STRATEGY FOR CLINICAL TRIALS}

In Table 1 we present the optimal search strategy to be used with LILACS/CD-ROM, 27th edition, January 1997. The strategy is divided into the following three stages as defined in Dickersen ${ }^{4}$ et al. and replicated in the Cochrane Handbook: stage one (sets 1 - 9) includes terms with high precision; stage two (sets 10 - 28) includes terms with moderate precision; and stage three (sets 29 - 39) includes terms with low precision but with optimal browser sensitivity.

Table 1

Optimal search strategy for Clinical Trials in the LILACS.

Bireme interface, 27th edition:

\#1 Pt RANDOMIZED CONTROLLED TRIAL

\#2 Pt CONTROLLED CLINICAL TRIAL

\#3 Mh RANDOMIZED CONTROLLED TRIALS

\#4 Mh RANDOM ALLOCATION

\#5 Mh DOUBLE-BLIND METHOD

\#6 Mh SINGLE-BLIND METHOD

\#7 \#1 OR \#2 OR \#3 OR \#4 OR \#5 OR \#6

\#8 Ct ANIMAL AND NOT (Ct HUMAN and Ct ANIMAL)

\#9 \#7 AND NOT \#8

\#10 Pt CLINICAL TRIAL

\#11 Ex E05.318.760.535\$ <explode Mh CLINICAL TRIALS>

\#12 Ti clin\$ and (Ti trial\$ OR Ti ensa\$ OR Ti estud\$ OR Ti experim\$ OR Ti investig\$)

\#13 Ab clin\$ and ( $A b$ trial\$ OR Ab ensa $\$$ OR Ab estud\$ OR Ab experim\$ OR Ti investig\$)

\#14 Ti singl\$ OR Ti simple\$ OR Ti doubI\$ OR Ti doble\$ OR Ti duplo\$ OR Ti trebI\$ OR Ti tripI\$

\#15 Ti blind\$ OR Ti cego\$ OR Ti ciego\$ OR Ti mask\$ OR Ti mascar\$

\#16 Ab singl\$ OR Ab simple\$ OR Ab doubl\$ OR Ab doble\$ OR Ab duplo\$ OR Ab trebl\$ OR Ab tripl\$

\#17 Ab blind\$ OR Ab cego\$ OR Ab ciego\$ OR Ab mask\$ OR Ab mascar\$

$\# 18$ (\#14 and \#15) OR (\#16 and \#17)

\#19 Mh PLACEBOS

\#20 Ti placebo\$

\#21 Ab placebo\$

\#22 Ti random\$ OR Ti randon\$ OR Ti casual\$ OR Ti acaso\$ OR Ti azar OR Ti aleator\$

\#23 Ab random\$ OR Ab randon\$ OR Ab casual\$ OR Ab acaso\$OR Ab azar OR Ab aleator\$

\#24 Mh RESEARCH DESIGN

\#25 \#10 OR \#11 OR \#12 OR \#13 OR \#15 OR \#16 OR \#17 OR \#18 OR \#19 OR \#20 OR \#21

\#26 Ct ANIMAL AND NOT (Ct HUMAN and Ct ANIMAL)

\#27 \#25 AND NOT \#26

\#28 \#27 AND NOT \#9

\#29 Ct COMPARATIVE STUDY

\#30 EXE05.337\$ <explode Mh EVALUATION STUDIES)>

\#31 Mh FOLLOW-UP STUDIES

\#32 Mh PROSPECTIVE STUDIES

\#33 Ti control\$ OR Ti prospectiv\$ OR Ti volunt\$ OR Ti volunteer\$

\#34 Ab control\$ OR Ab prospectiv\$ OR Ab volunt\$ OR Ab volunteer\$

\#35 \#29 OR \#30 OR \#31 OR \#32 OR \#33 OR \#34

\#36 Ct ANIMAL AND NOT (Ct HUMAN and Ct ANIMAL)

\#37 \#35 AND NOT \#36

\#38 \#34 AND NOT (\#9 OR \#25)

\#39 \#9 OR \#28 OR \#38

- Upper case denotes controlled vocabulary.

- Lower case denotes free-text terms. 


\section{DISCUSSION}

Using the optimal search strategy, are identifying 38,261 citations, in contrast with 3,505 citations retrieved by the CSRG have been identified search strategy. Only RCTs and CCTs will be selected from among these citations. Under the auspices of the Cochrane Collaboration, with each new edition of LILACS, we will be locating ${ }^{5}$ new RCTs and CCTs for the Cochrane Controlled Trials Register in the Cochrane Library.

In addition, we will be working retrospectively by locating clinical trials in old records of LILACS, through the CLINT-LAC PROJECT (Clinical Trials in the Latin American and Caribbean Project). This effort is being coordinated by the Brazilian Cochrane Center (http:// www.epm.br/cochrane).

At present, of the 31 Cochrane Reviews Groups, only the CSRG is using LILACS. Just two others, the HepatoBiliary and Peripheral Vascular Disease Reviews Groups, mention LILACS as an electronic Database that will be searched in the near future. We observed this after verifying the search strategy of each group ${ }^{6}$.

As non-English-language references are underrepresented in MEDLINE, and only published articles are included, there exists the potential for publication bias ${ }^{4,7}$. ${ }^{10}$ and language bias $^{11,12}$. Thus, the inclusion of LILACS in any search strategy should be mandatory.

As for technology requirements, during installation of the DOS-based software for LILACS/CD-ROM, an interface for three languages is available, so that opting to use English for the search is easy. The principal difficulty is that saving the strategy to floppy disk is impossible. Only expert knowledge will resolve this problem.

An update of the search strategy could be necessary. The headings and free text search terms requiring evaluation are: CROSSOVER TRIAL, VERSUS, PROPHILATIC THERAPEUTIC TRAIL. It is fundamental to understand some important user principles $^{13}$ in selecting MeSH or Non-MeSH terms for database searches.

The search strategy for questions concerning patients has three parts: disease, intervention, and study design ${ }^{14}$. Up to now, all discussion has been relevant only for the search strategy for locating study design; it has failed to consider the search strategy for identifying the disease and the intervention.

The search expression for locating clinical trials/ study design is: [(Disease AND Intervention) AND StudyDesign]. Analogously, it will be necessary to elaborate a search strategy for the disease and the intervention using headings and text free. The headings could verify the means, exploding if necessary. Text free (subject) will be synonyms, plural, different manner of writing, and correspondent words in English, Portuguese and Spanish languages will be indispensable. Obviously, further development is necessary in this area.

In conclusion, through constant efforts to elaborate and improve a search strategy for electronic databases, we are approaching the ideal. We believe that this collaborative work is the best way to reduce bias in locating and selecting clinical trials.

\section{RESUMO}

Objetivo: Divulgar a estratégia otimizada de pesquisa de ensaios clínicos na base de dados Latino-Americana e do Caribe de Informacoes em Ciências da Saúde (LILACS). Ela foi elaborada baseada na estratégia recomendada pelo Cochrane Collaboration para identificação de ensaios clínicos no MEDLINE. Tipo de estudo: Informe técnico. Local: Unidade de Ensaios Clínicos e Meta-Análise, Universidade Federal de São Paulo, em associação com o Centro Cochrane do Brasil, São Paulo, Brasil. (http:/ /www.epm.br/cochrane). Dados; A LILACS/CD-ROM (Base de dados Latino-Americana e do Caribe de Informaçōes em Ciências da Saúde), $27^{2}$ edição, janeiro/1997, é produzida pela BIREME (Centro Latino-Americano e do Caribe de Informaçōes em Ciências da Saúde). Indexa 670 revistas da região, com resumos em inglês, português e espanhol; destas, 41 indexadas pelo MEDLINE-EMBASE. Possue 168.902 citaçōes desde 1982, 104.016 são em humanos, 38.261 citações são potencialmente ensaios clínicos. A estratégia foi elaborada combinado descritores e palavras livres não três línguas, adaptando a interface da LILACS. Nós estaremos trabalhando para localizar ensaios clínicos no LILACS para a Base de Dados Cochrane de Ensaios Clínicos Controlados. Este esforço esta sendo coordenado pelo Centro Cochrane do Brasil. 


\section{REFERENCES}

1. Mulrow $C D$, Oxman $A D$ (eds). Locating and Selecting Studies. Cochrane Collaboration Handbook [updated 9 December 1996]; Section 5. Available in The Cochrane Library [database on disk and CDROM]. The Cochrane Collaboration; Issue 1. Oxford: Update Software; 1997. Updated quarterly.

2. Centro Latino-Americano e do Caribe de Informações em Ciências da Saúde. LILACS/CD-ROM. 27th edition, BIREME, 1997. (URL: http://www.bireme.br)

3. Adams C, De Jesus Mari J, White P (eds.) Schizophrenia Module of The Cochrane Database of Systematic Reviews, [updated 02 December 1996]. Available in The Cochrane Library [database on disk and CDROM]. The Cochrane Collaboration; Issue 1. Oxford: Update Software; 1997. Updated quarterly. Available from: BMJ Publishing Group, London.

4. Dickersin K, Scherer R, Lefebvre C. Identifying relevant studies for systematic reviews. BMJ 1994; 309:1286-91.

5. Dickersin K, Larson K. Establishing and maintaining an international register of RCTs. In: Cochrane Collaboration Handbook. Oxford: The Cochrane Collaboration, 1995 [updated 14 July 1995]. Available in: The Cochrane Library [database on disk and CDROM]. Oxford: Update Software, 1997; Issue 1. Updated quarterly. Available from: BMJ Publishing Group, London.

6. The Cochrane Collaboration. The Cochrane Library [database on disk and CDROM]. Oxford: Update Software, 1997; Issue
1. Updated quarterly. Available from: BMJ Publishing Group, London.

7. Dickersin K, Chan S, Chalmers TC, Sacks HS, Smith H. Publication bias and clinical trials. Controlled Clin Trials 1987; 8:343-53.

8. Easterbrook PJ, Berlin JA, Gopalan R, Matthews DR. Publication bias in clinical research. Lancet 1991; 337:86772.

9. Hetherington J, Dickersin K, Chalmers I, Meinert CL. Retrospective and prospective identification of unpublished controlled trials: lessons from a survey of obstetricians and pediatricians. Pediatrics 1989; 84:374-80.

10. Kleijnen J, Knipschild P. The comprehensiveness of Medline and Embase computer searches. Searches for controlled trials of homeopathy, ascorbic acid for common cold and ginkgo biloba for cerebral insufficiency and intermittent claudication. Pharm Weekbl Sci 1992; 14:316-20.

11. Smith BJ, Darzins PJ, Quinn M, Heller RF. Modern methods of searching the medical literature. Med J Aust 1992; 157(9):603-11.

12. Ramos-Remus C, Suarez-Almazor M, Dorgan M, GomezVargas A, Russell AS. Performance of online biomedical databases in rheumatology. J Rheumatol 1994; 21(10):191221.

13. Lowe HJ, Barnett GO. Undestanting and using the medical subject headings $(\mathrm{MeSH})$ vocabulary to perform literature studies. JAMA 1994;271:1103-1108.

14. McKIBBON, KA, WALKER-DILKS CJ. How to search for an article about diagnosis. ACP J Club 1994;121(1):A10. 